\title{
EDITORIAL
}

\section{Outcome from mechanical ventilation}

\author{
J-L. Vincent
}

The prognostic assessment of patients requiring mechanical ventilation has two important aspects. Firstly, it has sound therapeutic implications, derived from a better understanding of the factors influencing outcome. Secondly, it has important ethical implications, in helping to identify the patients who are not likely to benefit from mechanical ventilation. In these patients, the use of mechanical ventilation would only add to their discomfort, prolong suffering, and also add useless costs, at a time when health care resources are becoming limited $[1,2]$.

In this issue of the Journal, JimENEZ et al. [3] evaluated the outcome of 118 patients, 76 being ventilated for more than $72 \mathrm{~h}$. Thirty three $(28 \%)$ of these patients died. In the population studied, the best predictors of outcome were the number of associated complications and the degree of severity of the disease, as assessed by the simplified acute physiology score (SAPS), the degree of hypoxaemia, and the age of the patients. A logistic regression analysis revealed that the exclusion of the oxygenation index and the age did not reduce the prognostic assessment, indicating that the degree of global impairment was the major determinant of outcome.

One should emphasize that the study by JIMENEZ et al. [3], like those of others [4-8], included a mixture of underlying diseases, and the prognosis may be different in adult respiratory distress syndrome (ARDS), chronic obstructive pulmonary disease (COPD) and in other diseases. The present study included more than one third of postsurgical and traumatized patients, whose prognosis is known to be good [8], and only $8 \%$ of patients with ARDS. This can account for the Intensive Care Unit (ICU) mortality rate of only $28 \%$, whilst this mortality rate was usually around $50 \%$ in other studies $[4,6,8]$.

In patients with ARDS, the degree of hypoxaemia, and especially its time course, is an important prognostic factor [9-11], even though death is less commonly due to refractory hypoxaemia than to multiple organ failure [12]. However, ARDS is a heterogeneous syndrome, and the fatality rate also depends on the underlying problem. For instance, mortality is much higher when ARDS is due to sepsis than when it is due to fat embolism or aspiration of gastric content [13].

It is clear that the prognosis is related more to the degree of lung impairment in patients with COPD with other causes of respiratory failure [13]. Incidently, there have recently been very few reports on the outcome from

Correspondence: J-L. Vincent, Dept of Intensive Care, Erasme University Hospital, Route de Lennik 808, B-1070 Brussels, Belgium. mechanical ventilation in COPD patients, and it would be interesting to see whether changes in ventilatory management (especially the use of noninvasive mechanical ventilation) have influenced the outcome.

The study by JIMENEZ et al. [3] is in agreement with previous studies, indicating that the prognosis in patients requiring mechanical ventilation is determined by three major factors:

1. The cause of mechanical ventilation. It is clear that the outcome is poorer in patients who are ventilated after prolonged cardiopulmonary resuscitation than in patients with transient postoperative failure or with drug intoxication [8, 14-16].

2. The number of organs failing and the number of complications [4, 13]. Application of a severity index like the SAPS score has been sometimes, but not always [17], found useful.

3. The age and the degree of physiology reserve. Several studies $[6,8,15,18-20]$, but not all [4, 14], identified age as an important factor. A low serum albumin level [7], or the presence of cachexia [17], as signs of altered functional status have also been recognized as indicators of poor prognosis.

Once mechanical ventilation is initiated, the prognosis may also be related to its duration. For instance, SPICHER and WHITE [8] found that only 39\% could be discharged from ICU when the duration of mechanical ventilation exceeded 10 days. A recent study indicated that prolonged mechanical ventilation may not be associated with a greater ICU mortality but with a greater one year mortality rate [21].

One should indeed emphasize that success of weaning from mechanical ventilation, ICU survival, and long-term survival represent three different aspects. Roughly one half of the ICU survivors will be alive one year later. For instance, STAUFFER et al. [15] observed a successful weaning in $67 \%$ of patients, an ICU survival of $61 \%$, a hospital survival of $50 \%$, and a survival rate one year later of only $30 \%$. Similarly, ELPERN et al. [6] reported that one half of their patients died in the first year after discharge. In patients ventilated for 10 days or more SPICHER and White [8] observed an acute survival of 39\%, and one year survival of $29 \%$. DAvis et al. [1] reported a hospital survival of $44 \%$ and a 2 yr survival of $28 \%$.

What are the clinical implications of these observations? Let us return to the two aspects outlined initially. In terms of therapeutic implications, it appears that fatal cases are more commonly related to extrapulmonary than to pulmonary factors. This strongly suggests that mechanical ventilation is less a form of treatment than a 
form of organ support. This explains the difficulty in showing that any ventilatory technique can improve outcome. This should not temper our efforts to improve our ventilatory management, but the aim is generally more to limit the duration of mechanical ventilation and to prevent complications than to improve survival. These observations also stress the importance of considering the patient as a whole, rather than focusing attention on only one organ, namely the lung.

Concerning the ethical implications, we are left with the difficulty in objectively predicting the prognosis of ventilated patients. No single factor should be used alone to deny the use of mechanical ventilation. In particular, advanced age cannot, by itself, represent an obstacle to the use of mechanical ventilation $[14,20,22]$. The use of a severity index, such as the SAPS score used in the study by JIMENEZ et al. [3], or the more recent SAPS II Score [23], is not very helpful in this prognostic assessment. There are at least 10 reasons for this:

1. As mentioned above, the cause of mechanical ventilation is the most important determinant of outcome, and a simple scoring system cannot be valid for all groups of patients. As an example the APACHE II score is not reliable in patients with coronary problems, cardiogenic pulmonary oedema, burns trauma, or drug intoxication $[20,24]$.

2. These scoring systems are usually established only $24 \mathrm{~h}$ after ICU admission, and the decisions regarding the use of mechanical ventilation often come earlier.

3. All scoring systems are influenced by therapy. For instance, profound hypotension may have been corrected by high doses of vasopressor agents. Importantly, it is throughout the first $24 \mathrm{~h}$ that the score will be influenced by therapy.

4. All scoring systems remain subjective, especially in the choice of a primary diagnosis and the assessment of chronic health status.

5. All scoring systems are subject to selection bias and lead-time bias, i.e. there can be differences in selection criteria and variations in the evolution of the illness prior to ICU admission.

6. Scoring systems may not be very superior to the outcome assessment by doctors and nurses [25].

7. Simplicity and accuracy can hardly be combined. Scoring systems should include easily measurable and widely available parameters that could be combined in a simple calculation. Most scoring systems are relatively simple but not very accurate. The recent APACHE III score is the most sophisticated, but is also less easily manageable: such a system has become protected and access to it quite expensive. Nevertheless, no system will ever be highly accurate.

8. Scoring systems evaluate only the changes of survival; whereas, the quality of life is also an important determinant.

9. Perhaps most importantly, scoring systems cannot be applied to decisions concerning individual patients, because they lack sufficient sensitivity and specificity to dictate such individual decisions.

10. Nevertheless, there is a risk of abusive applications of scoring systems in ethical decisions. In particular, some hospital administrators have started to use them as tools to influence medical decisions, with the aim of improving the performance of the ICU.

Thus, no scoring system is very helpful in assessing the prognosis of patients requiring the use of mechanical ventilation. When deciding whether a patient can benefit from mechanical ventilation, we are thus left with our clinical judgement. It is well-established that there is no real difference between withholding (not starting mechanical ventilation) and withdrawing (discontinuing mechanical ventilation), so that mechanical ventilation could be initiated even when the eventual benefit from this intervention is far from established. The overall situation could be re-evaluated later [26], even though doctors feel less comfortable with withdrawing than withholding [27], especially when the patient is conscious. I am afraid that the most sophisticated analysis, using the best computer program will not help us very much with this. Medicine will remain an Art.

\section{References}

1. Davis II H, Lefrak SS, Miller D, Malt S. Prolonged mechanically assisted ventilation. J Am Med Assoc 1980; 243: 43-45.

2. Thoner J. Outcome and costs of intensive care. A follow-up study on patients requiring prolonged mechanical ventilation. Acta Anaesthesiol Scand 1987; 31: 693-698.

3. Jimenez P, Torres A, Roca J, Cobos A, Rodriguez-Roisin R. Arterial oxygenation does not predict the outcome of patients with acute respiratory failure needing mechanical ventilation. Eur Respir J 1994; 7: 730-735.

4. Gillespie DJ, Marsh HM, Divertie MB, Meadows JA. Clinical outcome of respiratory failure in patients requiring prolonged $(>24 \mathrm{~h})$ mechanical ventilation. Chest 1986; 90: 364-369.

5. Swinburne AJ, Fedullo AJ, Bixby K, Lee DK, Wahl GW. Respiratory failure in the elderly. Analysis of outcome after treatment with mechanical ventilation. Arch Intern Med 1993; 153: 1657-1662.

6. Elpern EH, Larson R. Douglas P, Rosen RL, Bone RC. Long-term outcomes for elderly survivors of prolonged ventilator assistance. Chest 1989; 96: 1120-1124.

7. Papadakis MA, Browner WS. Prognosis of noncardiac medical patients receiving mechanical ventilation in a veteran's hospital. Am J Med 1987; 83: 687-692.

8. Spicher JE, White DP. Outcome and function following prolonged mechanical ventilation. Arch Intern Med 1987; 147: 421-425.

9. Bone RC, Maunder R, Slotman G, et al. An early test of survival in patients with the adult respiratory distress syndrome. The $\mathrm{PaO}_{2} / \mathrm{FIO}_{2}$ ratio and its differential response to conventional therapy. Chest 1989; 96: 849851.

10. Mancebo J, Artigas A. A clinical study of the adult respiratory distress syndrome. Crit Care Med 1987; 15: 243-246.

11. Villar J, Villarlobos J, Bolanos J, Manzano JL. Prognostic value of the pulmonary function in acute respiratory failure. Clin Intens Care 1990; 1: 157-161.

12. Montgomery BA, Stager MA, Carrico J, et al. Causes of mortality in patients with the adult respiratory distress syndrome. Am Rev Respir Dis 1985; 132: 485-491. 
13. Hudson LD. Survival data in patients with acute and chronic lung disease requiring mechanical ventilation. Am Rev Respir Dis 1989; 140: S19-S24.

14. Pesau B, Flager S, Berger E, et al. Influence of age on outcome of mechanically-ventilated patients in an intensive care unit. Crit Care Med 1992; 20: 489-492.

15. Stauffer JL, Fayter NA, Graves B, Cromb M, Lynch JC, Goebel P. Survival following mechanical ventilation for acute respiratory failure in adult man. Chest 1993; 104: 1222-1229.

16. Gracey DR, Naessens JM, Krishan I, Marsh HM. Hospital and posthospital survival in patients mechanicallyventilated for more than 29 days. Chest 1992; 101: 211- 214.

17. Portier F, Defouilly C, Muir JF, the French Task Group for Acute Respiratory failure in Chronic Respiratory Insufficiency. Determinants of immediate survival among chronic respiratory insufficiency patients admitted to an intensive care unit for acute respiratory failure. Chest 1992; 101: 204-210.

18. Smith PF, Gordon IJ. An index to predict outcome in adult respiratory distress syndrome. Intens Care Med 1986; 12: 86-89.

19. Witek TJ, Schachter EN, Dean NL, Beck GJ. Mechanically-assisted ventilation in a community hospital. Arch Intern Med 1985; 145: 235-239.

20. Fedullo AJ, Swinburne AJ, Wah GW. APACHE II score and mortality in respiratory failure due to cardiogenic pulmonary edema. Crit Care Med 1988; 16: 1218-1223.

21. Quartin AA, Kett DH, Schein RM. Relationship of duration of ventilation support with last mortality in medical intensive care patients. Crit Care Med 1994; 22: A42 (Abstract)

22. Heuser MD, Case LD, Ettinger WH. Mortality in intensive care patients with respiratory disease. Is age important? Arch Intern Med 1992; 152: 1683-1688.

23. Le Gall J-R, Lemeshow S, Saulnier F. A new simplified acute physiology score (SAPS II) based on a European/ North American multicenter study. J Am Med Assoc 1993; 270: 2957-2963.

24. Vincent JL. Do we need a scoring system in the ICU? Réan Urg 1994; (in press).

25. Kruse JA, Thill-Baharozian MC, Carlson RW. Comparison of clinical assessment with APACHE II for predicting mortality risk in patients admitted to a medical intensive care unit. J Am Med Assoc 1988; 260: 1739-1742.

26. Vincent JL, Parquier JN, Preiser JC, Brimioulle S, Kahn RJ. Terminal events in the intensive care unit: review of 258 fatal cases in one year. Crit Care Med 1989; 17: 530-533.

27. Vincent JL. European attitudes towards ethical problems in intensive care medicine: results of an ethical questionnaire. Intens Care Med 1990; 16: 256-264. 